\title{
Significance of Proliferative Activity and DNA Ploidy in Pancreatic Cancer and Chronic Pancreatitis
}

\author{
Hagen Loertzer,' Raoul Hinze, ${ }^{1}$ Jürgen Knolle, ${ }^{2}$ \\ Friedrich-Wilhelm Rath,' and Adrian Schmassmann*,3 \\ 'Institute of Pathology, Martin-Luther-Universitat Halle-Wittenberg. Germany; \\ 'Institute of Pathology, Klinikum Bernburg, Germany; and 'Gastrointestinal Unit, \\ Department of Internal Medicine, Inselspital University of Bern, Switzerland
}

\section{Summary}

Background. Precise preoperative assessment of diagnosis and prognosis in patients with pancreatic tumors would facilitate improvement of treatment strategies. In this context, we evaluated the significance of the proliferative index and of static DNA cytophotometry in the diagnosis and prognosis of pancreatic tumors.

Methods. Consecutive surgical specimens from 26 patients with ductal pancreatic cancers and eight patients with chronic pancreatitis were investigated by:

1. Staging:

2. Conventional histological and cytological grading;

3. MIB-1 (Ki-67 labeling) proliferating index; and

4. Static DNA cytophotometry.

Results. All patients with chronic pancreatitis had a normal MIB-1 labeling index and a cuploid DNA content. In contrast, patients with pancreatic cancers rarely had a normal labeling index ( 1 of 26 patients) or a euploid DNA content ( 6 of 26 patients). Staging significantly correlated with survival time. However, it did not correlate with cytological criteria. Cytological criteria, such as conventional grading, MIB-1 proliferating index. and DNA ploidy, were not significantly correlated with survival time. Conventional grading was significantly correlated $(p<0.02)$ with proliferating index, but not with DNA ploidy.

Conclusion. Proliferating index and DNA ploidy are relevant cytological markers that can help to discriminate between chronic pancreatitis and pancreatic cancer. The prognostic significance of these markers in pancreatic cancer patients, however, seems to be less relevant than tumor stage and of limited relevance for the individual cancer patient.

Key Words: Pancreatic cancer: proliferative activity; MIB-1: Ki-67; static DNA cytophotometry; prognostic significance; survival.

\section{Introduction}

Despite recent improvements in surgical and multidisciplinary treatment, the overall prognosis for

Received December 9, 1998; Revised May 19, 1999: Accepted June 10. 1999

Author 10 whom all correspondence and reprint requests should he addressed: Leitender Arzt. Gastrointestinal Unit, Department of Internal Medicine. Inselspital. University of Bernc. 3010 Bern. patients with ductal pancreatic cancer remains poor (1). One important step in the diagnostic workup is the accurate preoperative assessment of prognosis (2). This would influence the decision of whether the tumor should be surgically resected. Thus far, tumor, node, and metastases (TNM) staging and grade of differentiation obviously correlated with survival $(3,4)$. Even though preoperative imaging has substantially facilitated accurate staging, pre- 
and even postoperative assessment of the biological behavior of the tumor still remain difficult.

Subjective grading can be supplemented by objective measurements of proliferative activity. Immunohistochemical methods for the detection of proliferation-related antigens, such as the Ki-67 antigen, are in frequent use. $\mathrm{Ki}-67$ is present in cycling cells with peak concentrations during the $\mathrm{G}_{2^{-}}$and $\mathrm{M}$-phases of the cell cycle and minimal concentrations in the $G_{0}$ or early $G_{1}$-phase. In this context, it is of interest that the monoclonal antibody (MAb) MIB- 1 is a true equivalent of $\mathrm{Ki}-67$. It can be detected in formalin-fixed, paraffin-embedded material (5). A number of studies have indicated that the MIB-1 proliferation index is of important prognostic significance for a variety of neoplasms, such as esophageal and renal tumors $(6,7)$.

Furthermore, there is a correlation between survival and DNA ploidy of cancer cells in most human malignant neoplastic diseases $(8,9)$. When the DNA ploidy of the neoplastic cells is a so-called aneuploid type, the malignant disease is usually rather aggressive, showing rapid progression. In contrast, tumors with a euploid DNA distribution pattern usually are less aggressive regarding long-term survival.

Pancreatic cancer, however, ranks among the most aggressive of human malignant neoplasms (1). The exact value of assessing proliferative activity and DNA ploidy in both preoperative cytological specimens and postoperative surgical specimens of pancreatic cancer is still highly debated and warrants further evaluation $(10-16)$. We assessed the prognostic significance of proliferative activity and DNA ploidy of malignant pancreatic cells using postoperatively saved histological sections.

\section{Materials and Methods}

\section{Subjects}

From 1989 to 1995,61 consecutive patients admitted to the Surgical Departement of the Martin-Luther University of Halle-Wittenberg for laparotomy owing to pancreatic tumors were retrospectively enrolled in the study. Twenty-six patients had typical ductal adenocarcinomas of the pancreas, and eight patients had chronic pancreatitis without malignancy. Formalin-fixed, paraffin-embedded surgical specimens from these 34 patients were examined. The following 27 patients were excluded:
1. Five patients with bile duct cancer;

2. Five patients with cancers of the ampulla of Vater;

3. Four patients with insulinoma;

4. Two patients with osteoclast-like giant cell tumors;

5. One patient with a neuroendocrine cancer;

6. One patient with a papillary cystic tumor;

7. Two patients with mucinous cystadenocarcinoma; and

8. Seven patients with liver or lymph node metastases without tissue from the primary tumor.

Pathologic staging was performed according to the criteria of the International Union Against Cancer (UICC) TNM staging system (17).

\section{Followup}

Patients were followed until death. All patients had undergone surgery and had their diagnosis of ductal pancreatic cancer confirmed by histology.

\section{Conventional histology}

Histological assessment and cytomorphological grading (grades 1-3) were performed on coded histological sections by one senior pathologist (J. K.) as previously described (17).

\section{MIB-I Immunohistochemistry \\ for Ki-67 Expression}

$\mathrm{Ki}-67$-expressing nuclei were stained and quantified with slight modifications from previous descriptions (7). In brief, deparaffinized tissue sections $(2.5 \mu \mathrm{m})$ were placed in citrate buffer $(\mathrm{pH} 6.0)$ and exposed to microwaves 3-6 times for $5 \mathrm{~min}$ at $600 \mathrm{~W}$ and then incubated for $1 \mathrm{~h}$ at $37^{\circ} \mathrm{C}$ with the MAb MIB-1 (dilution 1:10) (Dianova, Hamburg, Germany). Primary antibody was detected by the avidin-biotin-peroxidase complex technique using a commercially available reagent kit. MIB-1-labeled nuclei in lymph follicles were used as positive controls. Only slides that showed adequate MIB-1 labeling of nuclei in lymph follicles were used. The percentage of MIB-1-positive cell nuclei were determined by scoring a minimum of 400 cells in the most extensively immunostained areas (magnification: $\times 400$ ); all positive staining regardless of the intensity was regarded as positive. The counting was continued until the accumulated mean varied by $<5 \%$. The indices were calculated as the percentage of positively staining tumor cell nuclei of the total number of tumor cells counted. 


\section{DNA Cytophotometry}

DNA cytophotometry was performed essentially as previously described (7) with slight modifications. In brief, paraffin-embedded tissue was cut ( 8 $\mu \mathrm{m})$ and stained according to the Feulgen method. Cytometric assessment of the nuclear DNA content was performed using an image analysis system on "CYDOK" based on the light microscope "ZYTOPAN" (C. Reichert AG Wien, Austria). Absorption of the probes was determined at a wavelength of $560 \mathrm{~nm}$. For each patient, approx 100 nuclei were analyzed. The image was analyzed using morphometric criteria based on the site of the nuclei and their gray values, which ensured that both artifacts (dirt, duplets, and so forth) and inflammatory cells (lymphocytes, and so on) were excluded from the analysis. Determination of the diploid values was performed with normal ductal epithelial cells (coefficient of variability: $3.2 \%$ ); the diploid region of cellular DNA content was defined as $2 \mathrm{c} \pm 10 \%$. This definition was used to achieve adequate sensitivity and high specificity of the technique. DNA data were classified into four different histogram types according to Auer et al. (9).

\section{Statistical methods}

Survival was presented according to the KaplanMeier method, and the groups were compared with the log-rank test. Correlation analysis was performed according to Spearman as described by Sachs (18).

\section{Results}

\section{Clinical Characteristics, Pathological TNM Stage, and Surgical Procedure}

The median age of the patients at resection of the primary tumor was $60 \mathrm{yr}$ (range: $40-73 \mathrm{yr}$ ). There were 12 women and 14 men. Two, 8, 13, and 3 patients had a pathological tumor stage I, II, III. and IV, respectively. Two, 14, and 10 patients had a pathological T-stage $T_{1}, T_{2}$, and $T_{3}$, respectively. Thirteen patients each had a pathological $\mathrm{N}$-stage $\mathrm{N}_{0}$ and $\mathrm{N}_{1}$, respectively. Twenty-three and three patients had a pathological $M$-state $M_{0}$ and $M_{1}$, respectively. Stage IV with liver metastases was not diagnosed preoperatively. but histologically during surgery (threc patients had small $|<1 \mathrm{~cm}|$ liver metastases). These patients with small liver metastases received biopsy of both the pancreatic tumor and at least one liver metastases. The pancreatic tumor was resected in patients with stage I-III by the Whipple procedure. Patients with stage IV were treated by a biliary decompression procedure. The tumor was Iocalized in 20,4 , and 2 patients in the head, corpus, and cauda of the pancreas, respectively.

\section{Conventional Grading}

Cytomorphological grading showed high (grade I), medium (grade 2), or low (grade 3 ) differentiation in 1,16 , and 9 patients, respectively.

\section{MIB-I Proliferating Index}

The MIB-1 proliferation index was normal ( $<1 \%$ of all epithelial cells) in all patients with chronic pancreatitis and in one patient with a highly differentiated (grade 1) pancreatic cancer. Twelve. four. and nine cancer patients had low, medium, and high numbers of MIB-1-labeled cells, respectively (Table 1, Fig. 1).

\section{DNA Cytomorphometry}

All patients with chronic pancreatitis had a cuploid DNA content in the ductal epithelium in contrast to only $23 \%$ ( 6 of 26 patients) of pancreatic cancers. All conventional grade 3 differentiated tumors had cells with a DNA content $>9 c$. DNA histogram classification according to Aucr et al. was as follows: type I: no patient, type II: 4 patients, type III: 4 patients, and type IV: 18 patients (Table 1, Fig. 2).

\section{Survival}

TNM stage correlated significantly with survival time. The 24-mo survival rate of patients with a stage I or II tumor was $35 \%$. In contrast, conventional grading, MIB-1 proliferating index, and DNA ploidy did not correlate with survival time (Fig. 3).

\section{Correlation Analysis}

Staging did not significantly correlate with cytological criteria. Conventional grading was significantly correlated $(p<0.02)$ with MIB-1 proliferating index, but not with DNA ploidy. DNA ploidy did not show a significant correlation with conventional grading or MIB-I proliferating index.

\section{Discussion}

We evaluated the proliferative activity and D.NA ploidy of epithelial cells in benign and neoplastic pancreatic lesions. All patients with chronic pan- 
Table 1

Relationship Among MIB-1 Proliferating Index, Conventional Grading, DNA Ploidy, and Histogram Type of Auer in Patients with Pancreatic Cancer

\begin{tabular}{|c|c|c|c|c|}
\hline & \multicolumn{4}{|c|}{ MIB-1 proliferating index } \\
\hline & Normal & Low & Medium & High \\
\hline All cancers $(N: 26)$ & 1 & 12 & 4 & 9 \\
\hline \multicolumn{5}{|c|}{ Conventional grading (17) } \\
\hline Grade $1(N: 1)$ & 1 & 0 & () & 0 \\
\hline Grade $2(N: 16)$ & 0 & 10 & 2 & 4 \\
\hline Grade $3(N: 9)$ & 0 & 2 & 2 & 5 \\
\hline \multicolumn{5}{|c|}{ DNA ploidy (defined in Materials and Methods) } \\
\hline Euploid $(N: 6)$ & 0 & 5 & 0 & 1 \\
\hline Ancuploid ( $N: 20$ ) & 1 & 7 & 4 & 8 \\
\hline \multicolumn{5}{|c|}{ Histogram type of Auer et al. (9) } \\
\hline Type I $(N: 0)$ & ) & 0 & 0 & ) \\
\hline Type $2(N: 4)$ & 0 & 3 & 0 & 1 \\
\hline Type $3(N: 4)$ & 0 & 1 & 2 & 1 \\
\hline Type $4(N: 18)$ & 1 & 8 & 2 & 7 \\
\hline
\end{tabular}

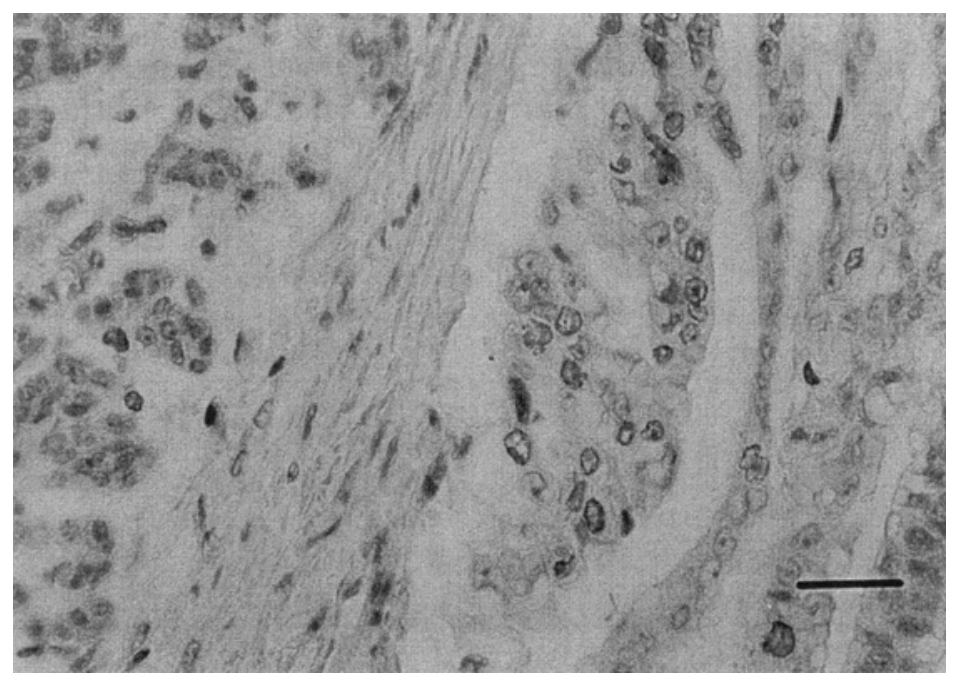

Fig. 1. MIB-1 immunostaining in a moderately differentiated pancreatic cancer (bar $100 \mu \mathrm{m}$ ).

creatitis showed a normal MIB-1 proliferating index and a euploid DNA content. In contrast, all but one patient with pancreatic cancer expressed increased MIB-1 proliferating indices and only $23 \%$ of pancreatic cancer patients had a euploid DNA content. Thus. MIB-I proliferating indices and DNA ploidy offer help in solving practical diagnostic problems, both in cytodiagnostic and histopathological specimens. It is well known that pathologists can be faced with a fine-needle aspiration or surgical biopsy specimen from a patient with a suspicious lesion in the pancreas for which the differential diagnosis is chronic pancreatitis or pancreatic cancer. Herc, the results of a cytometrical DNA analysis can be of paramount importance, since the finding of a high MIB-1 index or an aneuploid DNA content strongly indicates the existence of pancreatic cancer. This may be especially relevant if only minimal amounts 

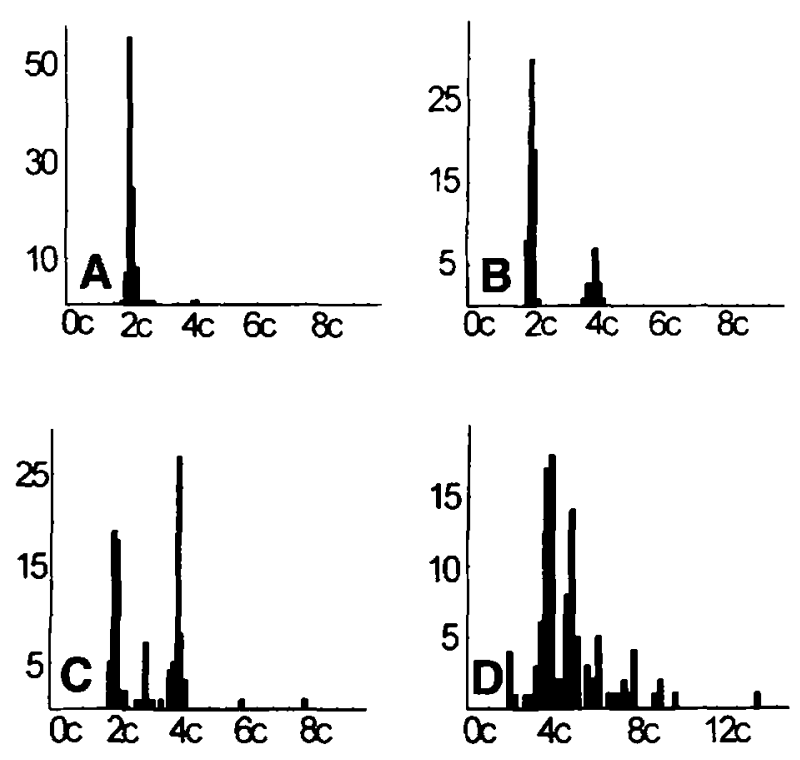

Fig. 2. Examples ol typical DNA histograms. (A) type I: cuploid. (B) type II: euploid. (C) type III: aneuploid, (D) type IV: aneuploid. (A) shows the DNA distribution pattern of a patient with chronic pancreatitis. (B-D) show the DNA distribution patterns of patients with pancreatic cancer.

of cytological material are available. Diagnosis of pancreatic cancer, however, should not exclusively rely on these parameters, since these changes may rarely also occur in precursor lesions. Furthermore. preoperative fine-necdle aspiration is debated because of the fear of tumor cell dissemination. Whenever possible brush cytology from the bile and pancreatic duct should be performed during cndoscopic retrograde cholangiopancreatography (ERCP), which is not associated with tumor seeding. Percutancous line-needle aspiration. which has a potential risk of tumor seeding, should be restricted to patients with no or minimal hope for cure by surgical resection.

With respect to cancer grading, poorly differentiated neoplastic cells usually have higher MIB-1 proliferating indices. For several neoplasms. both poor differentiation and high MIB-1 proliferating indices were reported as being associated with reduced survival time $(7,19.20)$. In pancreatic cancer, high MIB-I proliferating indices were found to correlate with short survival time (16). In our study. however, the MIB-I proliferating indices did not
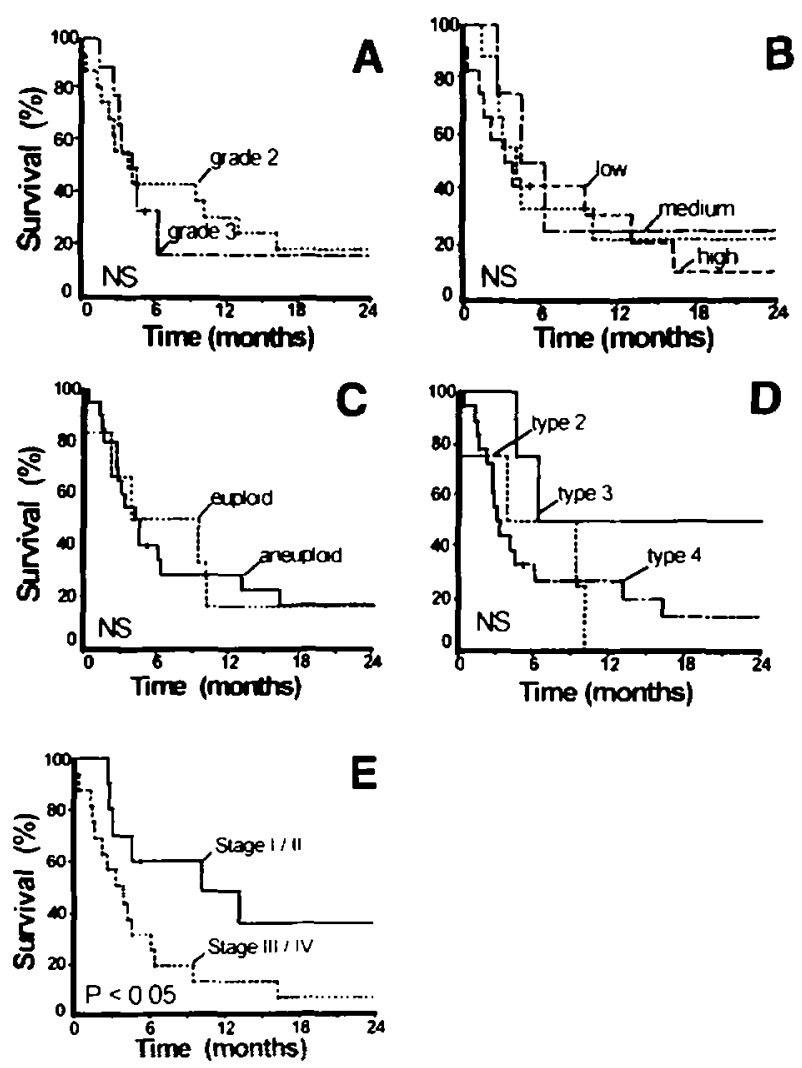

Fig. 3. Kaplan-Meier curves demonstrating the probability of survival of patients with pancreatic cancer. (A) Conventional cytological grading. (B) MIB-1 proliferating index. (C) DNA ploidy. (D) DNA histogram types, (E) pathological tumor stage.

reveal such corrclation with survival time. The variation in results between studies may be explained by differences in the study populations, the tumor stage. the surgical procedures, the immunohistochemical techniques, or the statistical methods. In contrast to the cytological markers, our study fully confirms previous studies on the prognostic effect of tumor stage on survival. Patients with stage I or II pancreatic cancer had a better prognosis than patients with stage III or IV.

DNA ploidy correlates with the aggressiveness and prognosis of various types of neoplasms. In pancreatic cancer, this correlation is less clear. The tumor ploidy was correlated with the survival times by some $(10-13,21,22)$. but not by all authors $(14,15)$. The survival time of the patients with a euploid DNA content in our study was not higher compared with 
that of the remaining $77 \%$ with an aneuploid DNA content. The discrepant results between studies may be explained by the reasons cited above, including technical problems associated with DNA flow cytometry. In contrast to many of the previously cited series using DNA flow cytometry, we applied static scanning DNA cytophotometry to utilize the possible benefit from the undisputed advantages of this method. These include the presence of an internal reference standard, the use of smaller tissue samples, the ability to distinguish neoplastic cells from nonncoplastic cells visually and the ability to generate histograms uncontaminated by debris and clumps of nuclei $(23,24)$.

DNA histogram classification according to Auer et al. did not show prognostic significance in our study. Furthermore, we were unable to find a significant correlation between the DNA content of neoplastic cells and the conventional grading or MIB-1 proliferating indices $(13,14,25)$.

One may conclude that the impact of proliferating index and DNA ploidy for an individual patient on survival is usually quite small. This does not exclude, however, that these parameters may be useful in some specific subgroups of patients (i.e., patients with an early tumor stage). More studies are necessary to define further potential subgroups of cancer patients for whom these cytological parameters may be useful.

In summary, MIB-1 proliferating index and DNA ploidy are relevant cytological markers that can help to discriminate between chronic pancreatitis and pancreatic cancer. The prognostic relevance of these cytological markers in pancreatic cancer patients, however, scems to be less relevant than tumor stage and of limited relevance for the individual cancer patient.

\section{References}

1 Gudjosson B. Cancer of the pancreas. Fifty years of surgery. Cancer 1987: 60: 2284-2303.

2 Schmassmann A. Halter F. Diagnosis and staging in pancreatic cancer: endoscopic retrograde cholangiopancreatography and endoscopic ultrasound. Dig Surg 1994; 11: 346-350.

3 Manabe T, Suzuki T, Tobe T. Factors influencing prognosis and indications for curative pancreatectomy for ductal adenocarcinoma of the head of the pancreas. Int I Pancreatol 1990: 7: 187-193.

4 Rugge M. Sonego F, Sessal F, Leandro G, Capella C, Sperti C. ct al. Nuclear DNA content and pathology in radically treated pancreatic carcinoma. The prognostic signilicance of ID.NA ploidy, histology and nuclear grade. Cancer 1996: 77: 459-466.

5 Cattoretti G, Becker MH, Key (3, Duchrow M. Schlüter C. Galle J. et al. Monoclonal antibodies against recombinant parts of the Ki67 antigen (MIBI and MIB3) detect prolifcrating cells in microwave-processed formalin-fixed paraffin sections. J Pathol 1992: 168: 357-363.

6 Youssef E.M. Matsuda T. Takada N, Osugi H. Higashino M, Kinoshita H, ct al. Prognostic significance of the MIB1 proliferation index for patients with squamous cell carcinoma of the esophagus. Cancer 1995; 76. 358 -366.

7 Jochum W, Schrocder S, al-Taha R, August C, Gross AJ. Berger J, et al. Prognostic significance of nuclcar DNA content and proliferative activity in renal cell carcinomas. A clinicopathologic study of 58 patients using mitotic count, MIB-1 staining, and DNA cytophotometry. Cancer 1996; 77: 514-521.

8 Aktin N, Kay R. Prognestic significance of modal D and other factors in malignant tumours, based on 1465. Cancer 1979: 40: 210-221.

9 Auer GU, Casperson TO, Wallgren AS. DNA content and survival in mammary carcinoma. Anal Quant Cyol 1980: 2: $161-165$.

10 Weger AR, Falkmer LG, Schwab G. Glaser K. Kemmler G, Bodner E. et al. Nuclear DNA distribution pattern of the parenchymal cells in adenocarcinomas of the pancreas and in chronic pancreatitis. A study of archival specimens using both image and flow cytometry. Gastroenterology 1990; 99: 237-242.

11 Weger AR. Glaser KS, Schwab G. Oefner D, Bodner E. Aucr GU. et al. Quantitative nuclcar DNA content in fine needle aspirates of pancreatic cancer. (Filt 1991: 32: $325-328$.

12 Allison DC. Bose KK. Hruban RH, Piantadosi S, Dooley WC., Boitnott JK, el al. Pancreatic cancer cell DNA content correlates with long-term survival after pancreatectomy. Ann Surg 1991: 214: 648-656.

1.3 Böttger TC, Störkel S, Wellek S. Stöckle M. Junginger T. Factors influencing survival after resection of pancreatic cancer: A $D N \wedge$ analysis and a histomorphologic sludy. Cancer 1994: 73, 63-73.

14 Herrera MF. Hecrden van JA. Katzmann JA. Weiland LH. Nagorney DM, Istrup D. Evaluation of DNA nuclear pattern as a prognostic determinant in resected pancreatic ductal adenocarcinoma. Ann Surg 1991: 215: $120-124$.

15. Hyöty M, Visakorpi T, Kallioniemic OP, Mattila J. Kaippala $P$, Nordbock J. Prognostic value of analysis of DNA in pancreatic adenocarcinoma by flow cytometry. Eur $J$ Surg 1991; 157: 595-600.

16 Lundin J. Nordling S, von Boguslawsky K, Roberts PJ, Haglund C. Prognostic value of $\mathrm{Ki}-67$ expression. ploidy and $S$-phase fraction in paticnts with pancreatic cancer. Anticancer Res 1995; 15: 26.59-2668.

17 Klöppel G. Solcia E. Longnecker DS, Capella C. Sobin LH, eds. Histological Typing of Tumors of the Exocrine pancreas. WHO. Springer, Berlin. 1996.

18 Sachs L. ed. Angewandte Statistik. Springer. Berlin. 1973. 
19 Gerdes J. Schwab U, Lemke H, Stcin H. Production of a mouse monoclonal antibody with a human nuclear antigen asscriated with cell prolifcration. Int J Cancer 1983: 31: $13-20$.

20 Lee CS. Differences in cell proliferation and prognostic significance of proliferating cell nuclear antigen and $\mathrm{Ki}$ 67 antigen immunoreactivity in in situ and invasive carcinomas of the extrahepatic biliary tract. Cancer 1996: 78: $1881-1887$

21 Johansson B. Bardi G, Heim S. Mandahl N, Mertens F, Bak-Jensen E. ct al. Nonrandom chromosomal rearrangements in pancreatic carcinomas. Cancer 1992; 69: 1674-1681.

22 Johansson B, Bardi G. Pandis N, Gorunova L, Backman L.P. Mandahl N. ct al. Karyotypic pattern of pancreatic ade- nocarcinomats correlates with survival and tumor grade. Int J Cancer 1994: 58: 8-13.

23 Duijndam WA, van Duijn P. The int7uence of chromatin on the stoichiometry of the Feulgen-Schiff procedure studied on model films. II. Investigations on films containing condensed or swollen chicken crythrocyte nuclei. IHistochem Cyochem 1975; 23: 891-900.

24 Klapperstück T, Wohlrab W. DNA image cytometry on sections as compared with image cytometry on smears and flow cytometry in melanoma. Cytomerry 1996; 25 : $82-89$.

25 Yoshimura T, Manabe T, Imamura T. Imanishi K, Ohshio G, Yamabe H, et al. Flow cytometry of nuclear DNA content of duct cell carcinoma of the pancreas. Cancer 1992; 70: $1069-1074$. 